\title{
Cardiotoxicity of First-Line Chemotherapy in Patients with Advanced Non-Small Cell Lung Cancer
}

\section{Daliborka Bursác ${ }^{1,2^{*}}$}

'Department for Chemotherapy, Institute for Pulmonary Diseases of Vojvodina, Sremska Kamenica, Serbia

${ }^{2}$ Faculty of Medicine Novi Sad, Univeristy of Novi Sad, Serbia

*Corresponding author: Daliborka Bursác, Department for Chemotherapy, Institute for Pulmonary Diseases of Vojvodina, Sremska Kamenica, Serbia, Tel: +381 64 2839713, E-mail: dadabursac@gmail.com, daliborka.bursac@mf.uns.ac.rs

Received: October 16, 2018; Accepted: November 13, 2018; Published: November 16, 2018

Copyright: ๑ 2018 Daliborka Bursác. This is an open-access article distributed under the terms of the creative commons attribution license, which permits unrestricted use, distribution, and reproduction in any medium, provided the original author and source are credited.

\begin{abstract}
Background: The main goal of chemotherapy is to destroy tumor cells at the maximum with minimal damage to healthy tissue, which is sometimes difficult to achieve due to the non-selectivity of chemotherapeutics. Cardiotoxicity become important in the past several years, as significant progress has been made in both, early diagnosis and the use of increasingly advanced antitumor drugs. The aim of this study was to establish the frequency of cardiotoxicity in the patients treated with the first-line chemotherapy (gemcitabine and cisplatin vs paclitaxel and carboplatin).
\end{abstract}

Methods: This prospective study included 240 non-small cell lung cancer patients at the clinical stages III and IV. Patients are divided into groups according to the type of chemotherapy (gemcitabine and cisplatin versus paclitaxel and carboplatin) and cardiovascular co-morbidities. Physical examination, electrocardiogram and NTproBNP (Nterminal proBrain Natriuremic Peptide) and troponin T levels were performed before and after the application of each cycle of chemotherapy. Echocardiography was performed before and after chemotherapy, as well as in the follow-up examinations every three months, a total of one year. Cardiac toxicity was determined based on the presence of cardiovascular symptoms, changes in the electrocardiogram, elevated levels of NTproBNP and troponin T and a decrease in left ventricular ejection fraction.

Results: In the study 184 patients $(76.7 \%)$ were male. The most frequent was adenocarcinoma, in 120 patients $(50 \%)$. Most common cardiovascular toxic effects were elevation in the level of NTproBNP $(44.85 \%)$, cardiac arrhythmias $(26.18 \%)$, venous thromboembolism (19.9\%) and decreased left ventricular ejection fraction $(6.96 \%)$. Patients treated with the first-line chemotherapy gemcitabine and cisplatin developed cardiotoxicity more frequently if they had a former history of cardiovascular diseases, but without statistical significance. In the group with paclitaxel and carboplatin, patients developed cardiotoxicity more frequently if they had a former history of cardiovascular diseases, and the statistical significance was registered at the first follow-up examination in stage III NSCLC patients $(p=0.037)$.

Conclusion: Chemotherapy induced cardiotoxicity frequently occurs in patients with cardiovascular comorbidities. Early detection and adequate therapy of cardiotoxicity is crucial for substantial recovery of cardiac function. Balance between the effectiveness of chemotherapy and the risk of cardiotoxicity requires close cooperation oncologists and cardiologists.

Keywords: Cardiotoxicity; Chemotherapy; Non-small cell lung cancer

\section{Introduction}

The main goal of chemotherapy is to destroy tumour cells at the maximum with minimal damage to healthy tissue, which is sometimes difficult to achieve due to the non-selectivity of chemotherapeutics. Cardiotoxicity become important in the past several years, as significant progress has been made in both, early diagnosis and the use of increasingly advanced antitumor drugs.

Cardiotoxicity was first observed in 1967 in children with leukaemia treated with doxorubicin, and it was more significant in 2009 when the International Association for Cardiology in Milan was established.

According to the time of occurrence, it can be acute (up to 2 weeks after chemotherapy), subacute ( 2 to 4 weeks after chemotherapy) and chronic (more than a month after the completion of the chemotherapy application). The appearance mechanism may be type I or so-called anthracycline cardiotoxicity and type II or cardiotoxicity occurring in the application of biological or target therapy (e.g. trastuzumab) (Table 1) $[1,2]$. With the increase in the number of new drugs, this classification is likely to undergo changes.

Cardiotoxicity has been thoroughly investigated in the administration of anthracyclines and HER-2 antagonists, most used in the treatment of breast cancer, but interest has spread to all drugs used in the treatment of malignant diseases. Many studies on pathophysiology and the genetic basis of cardiotoxicity are currently being carried out $[1,2]$.

The aim of this study was to establish the frequency of cardiotoxicity in the patients treated with the first-line chemotherapy (gemcitabine and cisplatin vs. paclitaxel and carboplatin) with and without previous cardiovascular diseases. 
Page 2 of 4

\begin{tabular}{|l|l|}
\hline Type I-Conventional Chemotherapy & Type II -Target Therapy \\
\hline Doxorubicin & Trastuzumab \\
\hline $\begin{array}{l}\text { Cell death, it starts with the first } \\
\text { application }\end{array}$ & Cell dysfunction \\
\hline Pathological findings in biopsy & Without typical changes in biopsy \\
\hline It depends on the cumulative dose & $\begin{array}{l}\text { Without the influence of a cumulative } \\
\text { dose }\end{array}$ \\
\hline Irreversible changes (cell death) & Reversible changes (cell dysfunction) \\
\hline $\begin{array}{l}\text { Risk factors: } \\
\text { Combined chemotherapy } \\
\text { Previous or concurrent radiotherapy } \\
\text { Age } \\
\text { Arterial hypertension }\end{array}$ & $\begin{array}{l}\text { Risk factors: } \\
\text { Previous or concurrent anthracycline } \\
\text { therapy } \\
\text { Age } \\
\text { Obesity }\end{array}$ \\
\hline
\end{tabular}

Table 1: Classification of the cardiotoxicity.

\section{Materials and Methods}

Prospective study, at the Institute of Pulmonary Diseases of Vojvodina, Sremska Kamenica, in the period from 2011 to 2013 included 240 patients with cytological or pathohistologically confirmed non-small cell lung cancer (NSCLC) at clinical stages III and IV, treated with first-line chemotherapy. Patients are divided into two groups, based on the stage of the disease. In the first group were patients in III and in the second group were patients at the IV stage of NSCLC. Each group was then divided into 4 subgroups of 30 patients, depending on the type of chemotherapy protocol (gemcitabine and cisplatin or paclitaxel and carboplatin) and the presence of cardiovascular comorbidity.

Before and after the application of each chemotherapy cycle a physical examination, electrocardiogram and NT-proBNP and serum troponin $\mathrm{T}$ values were performed. Echocardiography was performed before and after chemotherapy, as well as within the control examinations, every three months, for a total of one year. Cardiac toxicity was determined based on the presence of cardiovascular symptoms, changes in electrocardiogram, NT-proBNP and troponin T values, and the decrease in left ventricular ejection fraction-LVEF (Table 2). Treatment of cardiotoxic disorders was done according to the recommendations of the American Heart Association (AHA), the American College of Cardiology (ACC) and the European Society for Medical Oncology (ESMO) [3,4].

\begin{tabular}{|c|c|c|c|c|c|c|}
\hline & Inclusio & Before & After & $\begin{array}{l}\text { Follow } \\
\text { up } 1\end{array}$ & $\begin{array}{l}\text { Follow } \\
\text { up } 2\end{array}$ & $\begin{array}{l}\text { Follow } \\
\text { up } 3\end{array}$ \\
\hline & $\mathbf{n}$ & chemo & 0 & $\begin{array}{l}\text { after } 3 \\
\text { months }\end{array}$ & $\begin{array}{l}\text { after } 6 \\
\text { months }\end{array}$ & $\begin{array}{l}\text { after } 9 \\
\text { months }\end{array}$ \\
\hline $\begin{array}{l}\text { Physical } \\
\text { examination }\end{array}$ & + & + & + & + & + & + \\
\hline $\begin{array}{l}\text { Cardiovascular } \\
\text { symptoms }\end{array}$ & + & + & + & + & + & + \\
\hline Former diseases & + & & & & & \\
\hline Risk factors & + & & & & & \\
\hline ECG & + & + & + & + & + & + \\
\hline
\end{tabular}

\begin{tabular}{|l|l|l|l|l|l|l|}
\hline $\begin{array}{l}\text { Echocardiograp } \\
\text { hy }\end{array}$ & + & & & + & + & + \\
\hline NT pro-BNP & + & + & + & + & + & + \\
\hline Troponin T & + & + & + & + & + & + \\
\hline
\end{tabular}

Table 2: Study protocol.

\section{Results}

Of the 240 patients, there were $184(76.7 \%)$ men and $56(23.3 \%)$ women; ratio 3.3: 1 . The average age of all patients was $63.30 \pm 8.637$ years (range 34-84 years). Majority were diagnosed with adenocarcinoma (120 patients or 50\%), squamous cell lung cancer was confirmed in 108 patients (45\%), macro-cellular carcinoma in one patient $(0.4 \%)$ and in 11 patients $(4.6 \%)$ other types of cancer. In relation to the smoking status, there were $164(68.3 \%)$ smokers, 59 (24.6\%) former smokers and $17(7.1 \%)$ non-smokers. The patient characteristics were not significantly different between treatment arms (Table 3).

The most common comorbidities were arterial hypertension in 125 patients $(74.4 \%)$, diabetes in 30 patients $(17.86 \%)$, arrhythmias in 11 patients $(6.55 \%)$ and ischemic heart disease in 2 patients $(1.19 \%)$.

\begin{tabular}{|l|l|}
\hline Characteristics & Data \\
\hline Mean (Age) & 63.3 \\
\hline Range (years) & $34-84$ \\
\hline Male/female gender (number) & $184 / 56$ \\
\hline Smoking status (number) & 164 \\
\hline Current smoker & 59 \\
\hline Former smoker & 17 \\
\hline Non-smoker & \\
\hline Type of the carcinoma & 120 \\
\hline Adenocarcinoma & 108 \\
\hline Squamous cell lung cancer & 1 \\
\hline Macrocellular carcinoma & 11 \\
\hline Other types &
\end{tabular}

Table 3: Patient characteristics.

\begin{tabular}{|l|l|}
\hline Disease/State & Percentage (\%) \\
\hline NTproBNP elevation & 44.85 \\
\hline Cardiac arrhythmias & 26.18 \\
\hline Venous thromboembolism & 19.9 \\
\hline Decreased LVEF & 6.96 \\
\hline
\end{tabular}

Table 4: Cardiotoxicity.

Most common cardiovascular toxic effects were elevation in the level of NTproBNP (44.85\%), cardiac arrhythmias (26.18\%), venous 
thromboembolism (19.9\%) and decreased left ventricular ejection fraction-LVEF (6.96\%) (Table 4).

In patients with stage III NSCLC who received gemcitabine and cisplatin chemotherapy cardiotoxicity reported more frequently if they had previous cardiovascular diseases, but statistical significance was not established (after chemotherapy cycles and on follow up; $\mathrm{p}=0.792$, $\mathrm{p}=0.796, \mathrm{p}=0.434, \mathrm{p}=1.000, \mathrm{p}=0.792, \mathrm{p}=0.584$ and $\mathrm{p}=0.542$, respectively). In patients with stage IV NSCLC received the same chemotherapy protocol cardiotoxicity was more frequently in patients with cardiovascular comorbidities, but without statistical significance (after chemotherapy cycles and on follow up; $\mathrm{p}=0.313, \mathrm{p}=0.222$, $\mathrm{p}=0.371, \mathrm{p}=0.347, \mathrm{p}=0.278, \mathrm{p}=1.000$ and $\mathrm{p}=0.718$, respectively).

Cardiotoxicity in patients with stage III NSCLC who received paclitaxel and carboplatin chemotherapy was more common if they had previous cardiovascular disease and statistically significant difference was at the first control examination (one month after completion of chemotherapy $\mathrm{p}=0.037$ ). In patients with stage IV NSCLC received paclitaxel and carboplatin chemotherapy cardiotoxicity was more frequently in patients with cardiovascular comorbidities, but without statistical significance (after chemotherapy cycles and on follow up; $\mathrm{p}=0.228, \mathrm{p}=0.371, \mathrm{p}=0.390, \mathrm{p}=1.000, \mathrm{p}=0.129$, $\mathrm{p}=0.488$ and $\mathrm{p}=0.448$, respectively).

\section{Discussion}

We wanted to emphasize the importance of an adequate assessment of cardiac status to select patients for the chemotherapy in order to have better effect with less toxic side effects. Doxorubicin and trastuzumab are the drugs most tested in the field of cardiotoxicity, but, over time, interest in cardiotoxicity has spread to all drugs used in medical oncology. Usual chemotherapy protocols and radiation therapy induce cardiac toxicities that are frequently underappreciated. New treatments in lung cancer patients, such as immune checkpointblocking antibodies or tyrosine kinase inhibitors, may also exert these cardiac toxic effects [5]

In a large registry involving over 40.000 breast cancer patients from the SEER database, coronary artery disease, emphysema, diabetes, arterial hypertension, and peripheral vascular disease have been shown to be significant risk factors for the occurrence of cardiac insufficiency after chemotherapy [6].

Wachters et al. investigated the occurrence of cardiotoxicity in patients with advanced NSCLC treated with first-line chemotherapy gemcitabine plus cisplatin and epirubucine plus gemcitabine. The study included a total of 68 patients, III and IV stage of the disease, ECOG performance status of $0-2$, the average age of 61 years. The research involved patients without and patients with previous cardiovascular diseases [7].

The occurrence of cardiotoxicity was evaluated by measuring the left ventricle ejection fraction (LVEF) by MUGA scanning (radionuclide angiography or multi-gated acquisition), before and 12 weeks after chemotherapy. In patients receiving gemcitabine plus cisplatin chemotherapy cardiotoxicity in the form of a reduction in LVEF occurred in $23 \%$ patients (in $7 \%$ patient's reduction LVEF was greater than $20 \%$ of baseline values). In the second group of patients (gemcitabine plus epirubicin chemotherapy) cardiotoxicity occurred in $55 \%$ patients (in $13 \%$ patients' reduction LVEF was greater than $20 \%$ compared to baseline values).
Patients with previous cardiovascular disease, such as myocardial infarction, aortic stenosis or mitral regurgitation have been significantly reduced in the LVEF, but without statistical significance, $\mathrm{p}=0.265$. One of the conclusions of this study was that gemcitabine as part of polychemotherapy protocols can lead to subclinical heart damage.

In our clinical study, cardiotoxicity was defined according to the National Cancer Institute recommendations, we established a wider range of cardiotoxic events, and the reduction in left ventricular ejection fraction occurred in a total of $6.95 \%$ of patients.

In 2010, Hardy et al. published the results of a large study involving over 34.000 patients from the NSCLC stage I-IV who did not have previous cardiovascular disease at the time of diagnosis of the malignant disease [8]. Patients were divided into three groups; treated with chemotherapy, with radiotherapy and patients treated with chemo-radiotherapy.

We were particularly interesting for group of patients (9.4\%) who received only chemotherapy, as they were monitored for 12 months, which was the design and our study. During these 12 months, patients did not receive any other form of therapy, which enabled adequate monitoring of cardiovascular disorders. Ischemic heart disease and cardiac insufficiency were the most common cardiotoxicity that occurred in the group of patients receiving chemotherapy.

In their paper, Rowinski et al. reported that during paclitaxel chemotherapy, different reactions can occur in the form of bradyarrhythmia's, tachyarrhythmias, AV blocks, and ischemic events [9]. Walls et al. concluded that platinum-based agents may cause symptoms of the acute coronary syndromes. The risk continues for many years, and cisplatin can be detected in the serum at 20 years [10].

\section{Conclusion}

According to the results of our study, cardiotoxicity of chemotherapy is more common in patients with cardiovascular comorbidities. Establishing a balance between the effectiveness of chemotherapy and the risk of damage to the cardiovascular system requires close cooperation between the oncologist and the cardiologist, with the aim of creating individual therapy for each patient.

\section{Conflicts of Interest}

There are no conflicts of interest for the present study.

\section{References}

1. Sheppard RJ, Berger J, Sebag IA (2013) Cardiotoxicity of cancer therapeutics: Current issues in screening, prevention, and therapy. Front Pharmacol 4:19.

2. Albini A, Pennesi G, Donatelli F, Cammarota R, De Flora S, et al. (2010) Cardiotoxicity of anticancer drugs: The need for cardio-oncology and cardio-oncological prevention. J Natl Cancer Inst 102: 14-25.

3. AHA (2011) The American Heart Association. Available at: https:// www.heart.org/en/

4. Curigliano G, Cardinale D, Suter T, Plataniotis G, De Azambuja E, et al (2012) Cardiovascular toxicity induced by chemotherapy, targeted agents and radiotherapy: ESMO Clinical Practice Guidelines. Ann Oncol 23: 155-166.

5. Pérez-Callejo D, Torrente M, Brenes MA, Núñez B, Provencio M (2017) Lung cancer as a cardiotoxic state: A review. J Med Oncol 34: 159. 
Citation: Daliborka Bursác (2018) Cardiotoxicity of First-Line Chemotherapy in Patients with Advanced Non-Small Cell Lung Cancer. J Cardiovasc Dis Diagn 6: 345. doi:10.4172/2329-9517.1000345

Page 4 of 4

6. Pinder MC, Duan Z, Goodwin JS, Hortobagyi GN, Giordano SH (2007) Congestive heart failure in older women treated with adjuvant anthracycline chemotherapy for breast cancer. J Clin Oncol 25: 3808-3815.

7. Wachters FM, Graaf VWT, Groen HJ (2004) Cardiotoxicity in advanced non-small cell lung cancer patients treated with platinum and nonplatinum-based combinations as first-line treatment. Anticancer Res 24: 2079-2084.
8. Hardy D, Liu CC, Cormier JN, Xia R, Du XL (2010) Cardiac toxicity in association with chemotherapy and radiation therapy in a large cohort of older patients with non-small-cell lung cancer. Ann Oncol 21: 1825-1833.

9. Rowinsky EK, McGuire WP, Guarnieri T, Fisherman JS, Christian MC, et al. (1991) Cardiac disturbances during the administration of taxol. J Clin Oncol 9: 1704-1712.

10. Walls GM, Lyon AR, Harbinson MT, Hanna GG (2017) Cardiotoxicity following cancer treatment. Ulster Med J 86: 3-9. 